\title{
Artistic explorations of the brain
}

\section{Eberhard E. Fetz*}

Department of Physiology and Biophysics, University of Washington, Seattle, WA, USA

\section{Edited by:}

Idan Segev, The Hebrew University

of Jerusalem, Israel

Reviewed by:

Idan Segev, The Hebrew University

of Jerusalem, Israel

\section{*Correspondence:}

Eberhard E. Fetz, Department of Physiology and Biophysics,

University of Washington, Seattle, WA 98195-7290, USA.

e-mail: fetz@uw.edu
The symbiotic relationships between art and the brain begin with the obvious fact that brain mechanisms underlie the creation and appreciation of art. Conversely, many spectacular images of neural structures have remarkable aesthetic appeal. But beyond its fascinating forms, the many functions performed by brain mechanisms provide a profound subject for aesthetic exploration. Complex interactions in the tangled neural networks in our brain miraculously generate coherent behavior and cognition. Neuroscientists tackle these phenomena with specialized methodologies that limit the scope of exposition and are comprehensible to an initiated minority. Artists can perform an end run around these limitations by representing the brain's remarkable functions in a manner that can communicate to a wide and receptive audience. This paper explores the ways that brain mechanisms can provide a largely untapped subject for artistic exploration.

Keywords: art, brain, neural, collage, aesthetic

\section{INTRODUCTION}

All cognitive processes are ultimately performed by neurons in the brain, providing ample opportunities to elucidate the neural mechanisms that underlie artistic behavior and the appreciation of art. Several neuroscientists have explored the ways that graphic artists exploit the properties of the visual system to create resonant works (Livingstone, 1988, 2000, 2008; Zeki and Lamb, 1994; Zeki, 1999; Cavanagh, 2005; Liu and Miller, 2008). For example, the dominance of portraiture as an art form is clearly based on effective stimulation of the specialized face areas of the human brain (Zeki, 1999). The brain regions involved in processing artistic input have been extensively documented through modern imaging techniques (Vartanian and Goel, 2004; Di Dio et al., 2007; Kim and Blake, 2007; Fairhall and Ishai, 2008; Bosnar-Puretic et al., 2009; Chiu, 2009; Kowatari et al., 2009) and electrophysiological recordings (Bhattacharya and Petsche, 2002). Ramachandran has proposed several perceptual principles and described the neural mechanisms that may account for the aesthetic appeal of enduring art (Ramachandran and Hirstein, 1999; Ramachandran, 2011). Art historians have also expounded on the ways that an understanding of brain mechanisms can inform the appreciation of art (Clausberg, 1999; Cantz, 2000). The neural mechanisms underlying aesthetic experience have also been explored and elucidated in several publications (Rentschler et al., 1988; Ramachandran and Hirstein, 1999; Zeki, 1999; Vartanian and Goel, 2004; Nadal et al., 2008).

Interestingly, images of the brain and the spectacular forms of neural structures have their own aesthetic appeal. Larink has just produced a comprehensive review of how the brain has been depicted historically in various contexts that serve social and other functions (Larink, 2011). The wide range of images of neural morphology revealed by successively more sophisticated techniques, from early staining methods to contemporary multicolor reconstructions is lavishly illustrated in "Portraits of the Mind" (Schoonover, 2010). When appreciated by the right hemisphere rather than the left, the spectacular color images of intermingled neurons rival the aesthetic appeal of Richter's abstract paintings. Schoonover's book also illustrates the complex patterns produced by multichannel neural activity. A collection of artistic pieces inspired by the brain's anatomy and functions formed an eclectic exhibit in Rotterdam called "Neuro-artonomy," described in a book by the same name (Voogd, 1998). The book also includes many imaginative essays by neuroscientists and artists concerning each other's endeavors.

Beyond these reciprocal bridges between art and neuroscience there is a largely unexplored area of brain function as itself a subject for artistic representation. The neural networks in our brains effortlessly perform common miracles of perceiving the world, controlling volitional movements and performing higher functions like speech and thought. These cognitive functions are all produced by complex patterns of neural activity, but how mental events emerge from material mechanisms remains an enduring mystery. The remarkable relation between mind and brain has stimulated philosophers and scientists through the ages and holds a fascination for the layman. Neuroscientists have made considerable progress in elucidating the neural mechanisms underlying cognitive function, but their findings are disseminated in professional publications that are inaccessible to the larger population lacking the requisite training.

Many deep issues have remained impervious to scientific analysis. How does consciousness emerge from brain activity? How are coherent cognitive functions produced by the myriad impulses coursing through seemingly chaotic neural networks? What are the mechanisms that generate emotions, control thinking, mediate satori, etc.? While science remains unable to answer these questions, I believe that art can make an end run around the conceptual impasse. Art excels at rendering mysteries that surpass rational exposition. The components of the above questions are all amenable to various forms of graphic representation and their relationships can 
be explored by appropriate associations of images. Obviously such an approach would not answer these questions in scientific terms, but it can still communicate important relationships intuitively. Moreover, artistic approaches can communicate these issues to a wider audience than the neuroscience community. Such works could simply incorporate neural images as a reminder that brain mechanisms underlie mental events and behavior. But to attain aesthetic resonance such works should go beyond the images of neural forms and explore representations of the ways that these complex structures give rise to cognitive activity.

\section{ARTISTIC REPRESENTATIONS OF THE BRAIN}

Despite the brain's key role in mediating human experience, we have relatively few examples of artistic representations of brain mechanisms and functions. A possible early example is Michelangelo's "Creation of Adam" in the Sistine Chapel, which is said to employ an outline of the brain in God's cloud, as a metaphor for the neural basis of creativity (Meshberger, 1990; Lakke, 1999). Others have seen evidence of additional neuroanatomic images in the Sistine frescoes (Suk and Tamargo, 2010).

Depictions of brain mechanisms become particularly compelling when displayed in public exhibitions of walk-in renderings of neural images, accompanied by recordings of neural activity, as in the "Mindscape" project (O'Shea and Sneltvedt, 2006). The Mindscape exhibit, first presented in a Brighton church in 2004, was a multimedia artwork that had "resonance in the science of the brain." The artist Sol Sneltvedt was inspired to represent the neural mechanisms underlying dynamic states of mind and collaborated with neuroscientist Michael O'Shea to create an immersive audiovisual installation. Large-scale projections of neural structures and multiple soundtracks of neural activity surrounded viewers with a vivid representation of brain activity. The projections fluctuated between different neural images that were synchronized with audio tracks of neural recordings. Representing both fastscale electrical activity and slower chemical communications, the visualizations presented a rich experience of dynamic brain activity. Similarly, a current travelling exhibition called "BRAIN: The World inside Your Head" presents an elaborate multimedia exhibit designed to impress viewers with the workings of brain mechanisms that mediate mental experience (details of the exhibit and the location of its latest incarnation can be found via Google).

Excellent examples of artistic exploration of mind and brain are described in the paper by Goeffrey Koetsch in this Frontiers Special Topic issue (Koetsch, 2011). He illustrates the works of eight New England artists dealing with mental processes and alluding to neural mechanisms, presented in an exhibition called MINDmatters (see http://www.laconiagallery.org/ exhibit18.html).

A prolific contemporary artist whose works have been consistently inspired by the relationships between mind and brain is Todd Siler. Siler has produced innumerable striking images and installations representing the interactions between brain, mind and the world in varying levels of abstraction (see http://www.

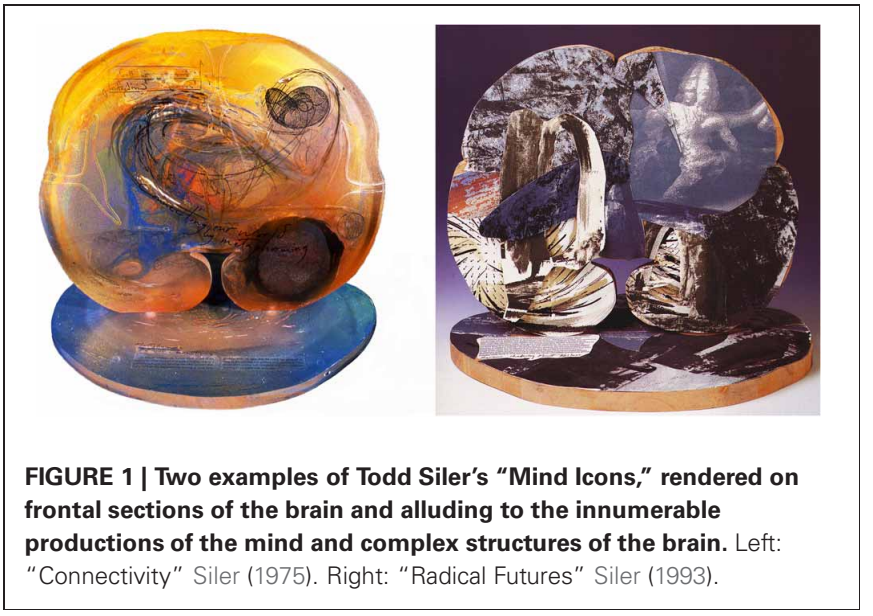

toddsilerart.com). Figure 1 illustrates two pieces from his extensive "Mind Icon" series, rendered on slabs shaped like frontal brain sections and painted with images representing mental and neural activity. His dramatic works and creative approaches are described in numerous publications (Siler, 1975, 1990, 1993), and in a comprehensive paper in this Special Topic issue (Siler, in press).

Another example inspired by brain function is the collage in Figure 2, which alludes to the types of neural interactions that mediate cognitive processing. The subject is the brain of Eric Heller, a physicist interested in wave mechanics, who has also explored aesthetic renderings of quantum processes (see http://www.ericjhellergallery.com). Heller's brain converts quantum events described by the Schrödinger equation into Matlab code that generates spectacular graphic patterns produced by quantum wave propagation and resonance. Such images lend themselves perfectly to representations of brain waves and reverberating neural activity, and are here combined with neural images. One of Heller's famous figures shows the cumulative pathways that electrons would produce when emerging from a central source and propagating over a potential field (Topinka et al., 2001); this image, shown on a cover of Nature, resembles a generic biological form, including the morphology of Golgi neurons (see prefrontal cortex in Figure 2). The collaged images in Figure 2 allude to the resonant interactions between frontal and occipital areas of the brain when creating visual art.

A third example (Figure 3) provides a metaphor of the conscious self emerging from the complex tangle of neural networks. The human figure may be recognized from its original incarnation in the Flammarion engraving, depicting an explorer breaking through the confines of the physical world to discover celestial realms beyond (http://en.wikipedia.org/wiki/ Flammarion_engraving). This piece is intended to be rendered with the white portion being a mirror surface, reflecting the real world.

\section{FUTURE OPPORTUNITIES}

The collages in Figures 1-3 illustrate the sort of representations through associated images that are possible with pictorial 


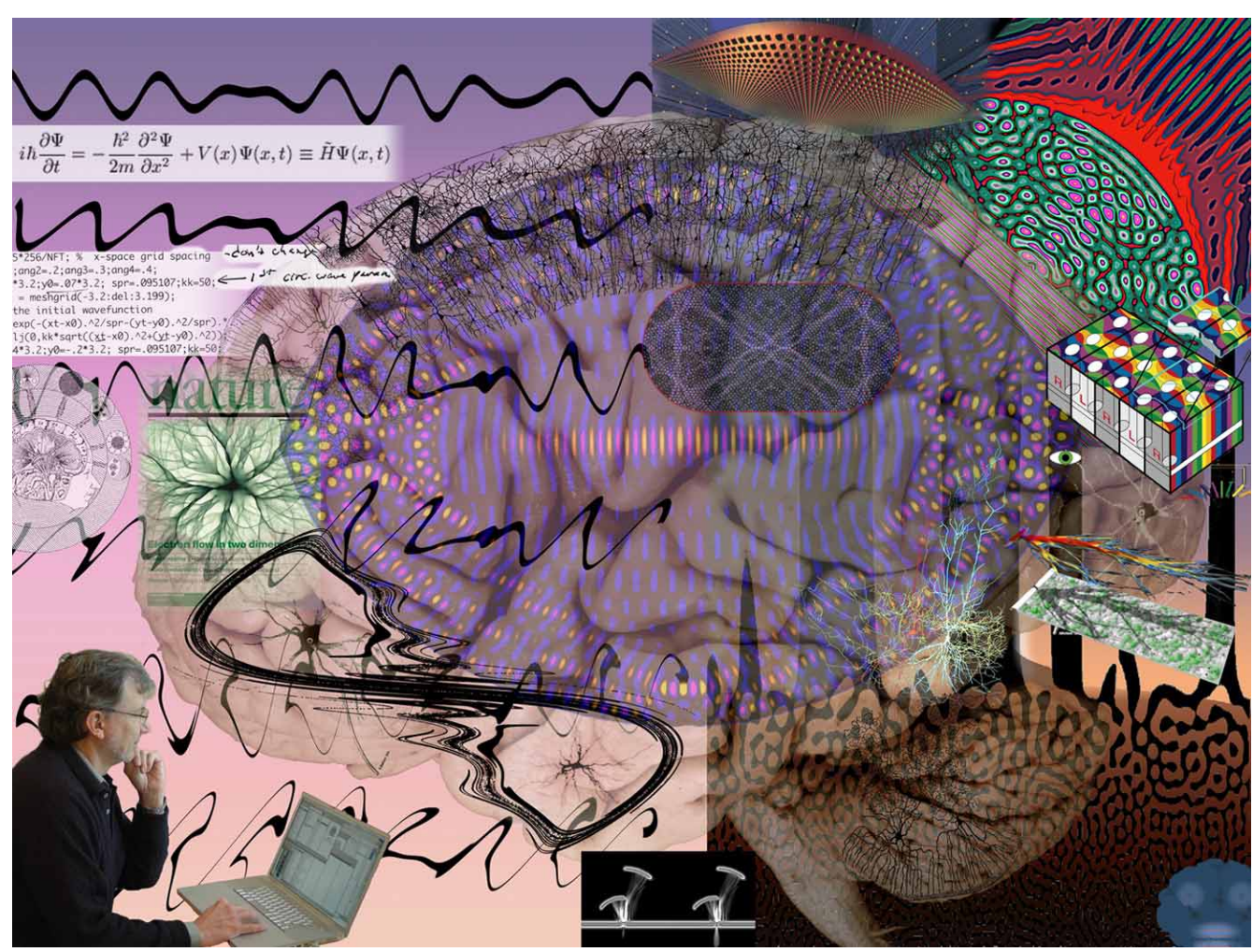

FIGURE 2 | "Resonant Transformations," a digital collage by the author. The geometric images were created by Eric Heller, using simulations of quantum dynamics and incorporated here to allude to dynamic neural interactions in the brain.

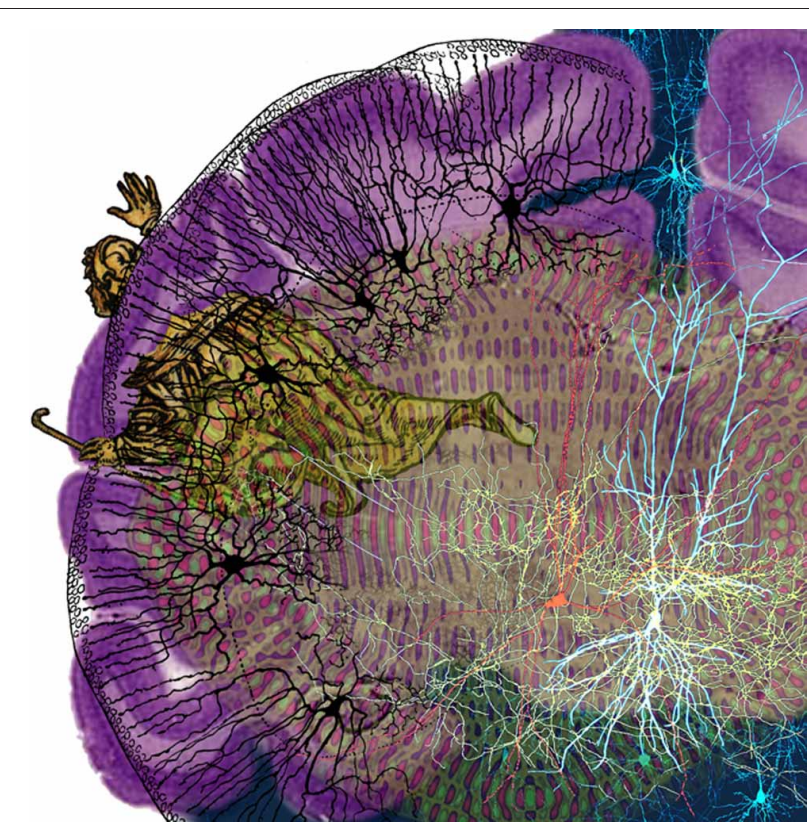

FIGURE 3 | "Awakening," by the author. The white portion of the image is intended to be rendered as a mirror surface reflecting reality.

Alternatively, the image can be rendered on clear glass, with the white portion transparent. presentation. More profound effects could be achieved with multimedia techniques. The dynamic operations of the brain can be effectively represented by videos of wave propagation through neural networks or the limitless contents of cognitive activity. Projecting these videos onto $3 \mathrm{D}$ structural renderings of brain networks could provide effective representations of functions emerging from forms. The works could even be made interactive by incorporating real-time videos of the observer, and could be designed to stimulate the viewer to recognize his own instantaneous brain activity.

A key advantage of art over science in representing brain function is its wider palette of discourse, allowing it to evoke associations that transcend objective thought. The mind-brain problem has remained refractory to rational resolution, but its underlying mechanisms may be approached by artistic representation and appreciated by aesthetic revelation. This presents a rich opportunity for artistically inclined neuroscientists, who understand the operations of brain mechanisms and can render insightful representations. The process of creating visualizations of brain function could even give neuroscientists righthemisphere insights that could inform their left-hemisphere investigations. This opportunity should also interest conceptually inclined artists, who have the requisite creative talents and are inspired to explore this largely untapped aesthetic realm. Their challenge would be to draw on the rich trove of current scientific information and breathe aesthetic 
life into the deeper issues. Finally, as demonstrated by the Mindscape project, there are ample opportunities for productive collaborations between artists and neuroscientists to create new works inspired by the resonant relations between mind, brain and reality.

\section{REFERENCES}

Bhattacharya, J., and Petsche, H. (2002). Shadows of artistry: cortical synchrony during perception and imagery of visual art. Brain Res. Cogn. Brain Res. 13, 179-186.

Bosnar-Puretic, M., Roje-Bedekovic, M., and Demarin, V. (2009). The art: neuroscientific approach. Acta Clin. Croat. 48, 367-370.

Cantz, H. (2000). Gehirn und Denken; Kosmos im Kopf. Dresden: Stiftung Deutsches Hygiene-Museum.

Cavanagh, P. (2005). The artist as neuroscientist. Nature 434, 301-307.

Chiu, H. C. (2009). Neurology of the arts. Acta Neurol. Taiwan. 18, 132-136.

Clausberg, K. (1999). Neuronale Kunstgeschichte: Selbstdarstellung als Gestaltungsprinzip. Wien \& New York: Springer.

Di Dio, C., Macaluso, E., and Rizzolatti, G. (2007). The golden beauty: brain response to classical and renaissance sculptures. PLoS One 2, e1201. doi: 10.1371/journal.pone.0001201

Fairhall, S. L., and Ishai, A. (2008). Neural correlates of object indeterminacy in art compositions. Conscious. Cogn. 17, 923-932.

Kim, C. Y., and Blake, R. (2007). Brain activity accompanying perception of implied motion in abstract paintings. Spat. Vis. 20, 545-560.

Koetsch, G. (2011). Artists and the mind in the 21 st century.
Front. Hum. Neurosci. 5, 110. doi: 10.3389/fnhum.2011.00110

Kowatari, Y., Lee, S. H., Yamamura, H., Nagamori, Y., Levy, P., Yamane, S., and Yamamoto, M. (2009). Neural networks involved in artistic creativity. Hum. Brain Mapp. 30, 1678-1690.

Lakke, J. P. (1999). Artful imaging of the brain. From logo to metaphor, about Michelangelo and Kiefer. Arch. Physiol. Biochem. 107, 1-14.

Larink, W. (2011). Bilder vom Gehirn: Bildwissenschaftliche Zugänge zum Gehirn als Seelenorgan. Berlin: Akademie Verlag GmbH.

Liu, A., and Miller, B. L. (2008). Visual art and the brain. Handb. Clin. Neurol. 88, 471-488.

Livingstone, M. S. (1988). Art, illusion and the visual system. Sci. Am. 258, 78-85.

Livingstone, M. S. (2000). Is it warm? Is it real? Or just low spatial frequency? Science 290, 1299.

Livingstone, M. S. (2008). Vision and Art: The Biology of Seeing. New York, NY: Abrams.

Meshberger, F. L. (1990). An interpretation of Michelangelo's Creation of Adam based on neuroanatomy. JAMA 264, 1837-1841.

Nadal, M., Munar, E., Capo, M. A., Rossello, J., and Cela-Conde, C. J. (2008). Towards a framework for the study of the neural correlates of aesthetic preference. Spat. Vis. 21, 379-396.

\section{ACKNOWLEDGMENTS}

I thank the Wissenschaftskolleg zu Berlin for providing the opportunity to create the digital collages in Figures $\mathbf{2}$ and $\mathbf{3}$, Eric Heller for providing some of the images in Figure 2, and Todd Siler for permission to reproduce the images in Figure 1.

O'Shea, M., and Sneltvedt, S. (2006) Mindscape: an attempt to visualize the workings of the brain. Leonardo 39, 455-457.

Ramachandran, V. S. (2011). The TellTale Brain. New York, NY: Norton.

Ramachandran, V. S., and Hirstein, W. (1999). The science of art. J. Conscious. Stud. 6, 15-51.

Rentschler, I., Herzberger, B., and Epstein, D. (1988). Beauty and the Brain: Biological Aspects of Aesthetics. Cambridge, MA: Birkhauser.

Schoonover, C. (2010). Portraits of the Mind. New York, NY: Abrams.

Siler, T. (1975). A.R.T. Strings: A Guide to the Works of Todd Siler. Greenwood Village, Colorado: PsiPhi Communications, LLC.

Siler, T. (1990). Breaking the Mind Barrier. New York, NY: Touchstone.

Siler, T. (1993). Cerebralism: Creating a New Millenium of Minds, Bodies and Civilizations. New York, NY: Ronald Feldman Fine Arts, Inc.

Siler, T. (in press). Neuro-impressions. Front. Neurosci.

Suk, I., and Tamargo, R. J. (2010). Concealed neuroanatomy in Michelangelo's Separation of Light From Darkness in the Sistine Chapel. Neurosurgery 66, 851-861.

Topinka, M. A., Leroy, B. J., Westervelt, R. M., Shaw, S. E., Fleischmann, R., Heller, E. J., Maranowski, K. D., and Gossard, A. C. (2001). Coherent branched flow in a two-dimensional electron gas. Nature 410, 183-186.

Vartanian, O., and Goel, V. (2004). Neuroanatomical correlates of aesthetic preference for paintings. Neuroreport 15, 893-897.

Voogd, K., ed. (1998). Neuro-Artonomy. Rotterdam: Neuro-artonomy.

Zeki, S. (1999). Inner Vision: An Exploration of Art and the Brain. Oxford: Oxford University Press.

Zeki, S., and Lamb, M. (1994). The neurology of kinetic art. Brain 117(Pt 3), 607-636.

Conflict of Interest Statement: The author declares that the research was conducted in the absence of any commercial or financial relationships that could be construed as a potential conflict of interest.

Received: 01 April 2011; accepted: 20 January 2012; published online: 07 February 2012.

Citation: Fetz EE (2012) Artistic explorations of the brain. Front. Hum. Neurosci. 6:9. doi: 10.3389/fnhum. 2012.00009

Copyright (c) 2012 Fetz. This is an openaccess article distributed under the terms of the Creative Commons Attribution Non Commercial License, which permits non-commercial use, distribution, and reproduction in other forums, provided the original authors and source are credited. 